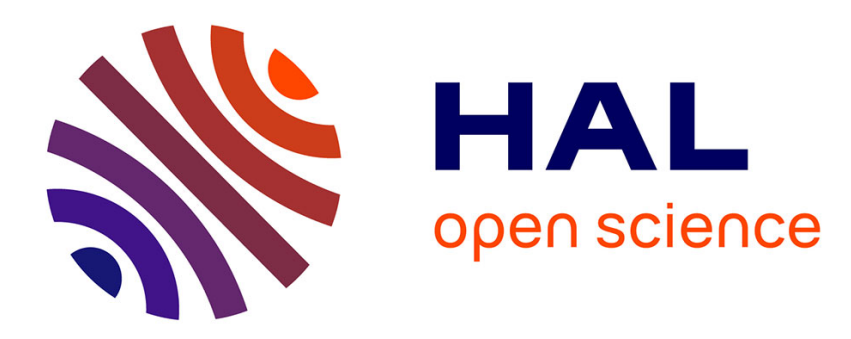

\title{
Synergizing Lean and Green for Continuous Improvement
}

Rythm Suren Wadhwa

\section{To cite this version:}

Rythm Suren Wadhwa. Synergizing Lean and Green for Continuous Improvement. IFIP International Conference on Advances in Production Management Systems (APMS), Sep 2014, Ajaccio, France. pp.154-161, 10.1007/978-3-662-44736-9_19 . hal-01387860

\section{HAL Id: hal-01387860 \\ https://hal.inria.fr/hal-01387860}

Submitted on 26 Oct 2016

HAL is a multi-disciplinary open access archive for the deposit and dissemination of scientific research documents, whether they are published or not. The documents may come from teaching and research institutions in France or abroad, or from public or private research centers.
L'archive ouverte pluridisciplinaire HAL, est destinée au dépôt et à la diffusion de documents scientifiques de niveau recherche, publiés ou non, émanant des établissements d'enseignement et de recherche français ou étrangers, des laboratoires publics ou privés. 


\title{
Synergizing lean and green for continuous im- provement
}

\author{
R. S. Wadhwa \\ Høgskole i Gjøvik \\ Gjøvik, 2802 Norway
}

\begin{abstract}
For many years small-medium enterprises (SMEs) have attempted to improve their manufacturing and environmental operation performance in a view to achieving competitiveness and operational excellence. This paper looks at the literature in order to investigate the relationship between lean and green management and their relationship to one another while keeping in mind their simultaneous implementation at a foundry SME. Separate literature streams have arisen to address issues in green and lean using systems engineering tools but research has largely neglected the intersection of the two. The presented research synthesizes the literature addressing the intersections of green and lean and suggests a research agenda to address gaps. Suggestions for implementing environmental management systems for sustaining continuous improvement activities have also been provided.
\end{abstract}

Keywords: Six Sigma, Systems Engineering, SME.

\section{Introduction}

Today's SMEs (Small-to-Medium sized Enterprises) need to address the increasing global competition, decreasing product life cycles and increasing customer demands. SMEs require more financial and technical assistance when compared to OEMs (Original Equipment Manufacturers) when moving from reactive measures for the end use of products to a more proactive consideration within environmentally benign continuous improvement in plant operation. [1] Improving environmental performance while keeping regulatory costs down is one of the key challenges affecting the future competitiveness of casting foundry SMEs.

Metalcasting produces a number of liquid, gas and solid waste streams, many of which could have an adverse affect on the environment. On the other hand, it also produces some positive impacts on the environment by preventing landfills of large amounts of scrap metal. In the US the foundry industry spends over $\$ 1.25$ billion/year 
to comply with federal, state and local government regulations, although this number does not include some smaller foundries, certain categories of environmental compliance costs from captive foundries reported under different industry classifications. [2] About $40 \%$ of compliance costs are used for control, treatment, and disposal of air pollutants and related sludge. Solid and hazardous waste disposal-sand bags and slagaccount for about 33\% of the compliance costs. (Figure 1) Environmental compliance costs are currently estimated to be $2 \%$ of the cost of a casting, which is expected to increase to $5 \%$ in the near future. Sand casters face major environmental issues related to treatment and disposal of spent sands that may be contaminated with toxic wates.

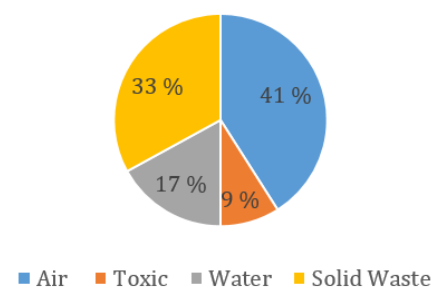

Fig. 1. Environmental cost by media

Manufacturing is a dominant sector in the European economy as well. The economic importance of this sector is evident: it provides jobs for approximately 34 million people; and produces an added value in excess of $€ 1500$ billion from 230000 enterprises with 20 or more employees [3]. However, it is widely perceived to be facing serious challenges. This is particularly true of the manufacturers located in the highcost regions.

Lean production is often described as both a philosophy and a set of working practices with the goal of achieving high levels of customer satisfaction through increased quality, reduced costs and world-class delivery performance. While there are separate streams of established research on green and lean issues, few authors have addressed the intersection of these in industrial SME scenarios. This is a critical oversight because firms may be missing synergies available through improved concurrent implementation; they may also be failing to address important tradeoffs that may arise when there are incompatibilities between strategic initiatives. For example, lean and green strategies are often seen as compatible initiatives because of their joint focus on waste reduction.

The ISO-9000 quality standard has been shown to be highly correlated with the adoption of ISO-14000 environmental standard. There is evidence of this relationship across both lean interfaces, but quality improvement has not been explored at the conjunction of all two strategies. The relationship yet to be explored at the interface of the two strategies. Green initiatives focus on reducing pollution, while this is not a priority driving lean. Managers in companies find it difficult to simultaneously implement these three strategies. For example, buyer-supplier alignment is addressed differently across the three interfaces. Buyers often focus on low costs, whereas suppliers may incur greater costs while attempting to provide more environmentally re- 
sponsible or higher quality products. Lack of development may be due to the exploratory nature of research regarding the relationships between green and lean.

Environmental management may also represent an untapped avenue for further reduction of manufacturing costs through more efficient use of natural resources [4][5]. The issue, however, of how to address the environmental management practices of vendors may prove to be a costly endeavour if not managed taking into consideration a number of important economic factors. To date there has been only limited anecdotal discussion of the legitimate incentives for SMEs to extend environmental management beyond their immediate boundaries.

The paper is organized as follows. Section II presents the research methodology followed by the industrial use case in section III. Section IV describes the suggested plan for continuous improvement and environmental performance management at SMEs and finally, the summary is presented in section V.

\section{Research Methodology}

Common drivers and barriers lead to both complementary and conflicting arguments across green and lean strategies. Synthesizing the literature in the areas of green and lean allows the researchers to draw inferences about a combined green and lean strategy. Four major factors motivate firms to adopt some combination of these strategies: cost reductions, customer demands, international standards such as ISO-9000 and ISO-14000, and risk management. Toyota is a good example of a firm that has successfully integrated a green and lean strategy in a global setting. The company's commitment is evident through its ISO certifications and financial investment into quality and environmental research and development. [6][7]

\subsection{Lean and Green manufacturing}

Lean manufacturing is based on the principles and working processes of the Toyota Production System, and has been defined as doing more with less [8]. Lean manufacturing's most distinguishing principle is the relentless pursuit of waste [9]. It has been most prominent in discrete, repetitive assembly-type operations. Liker [11] suggests that the goals of lean manufacturing are highest quality, lowest cost, and shortest lead time. It can be described as a multi-dimensional approach that encompasses a wide variety of management practices, including Just-in-Time (JIT), quality systems, work teams, cellular manufacturing supplier management, etc. in an integrated system [12]. Distribution and transportation operations networks are important operational characteristics that will affect green manufacturing value stream. [19] With the rapid increase of long-distance trade, supply chains are increasingly covering larger distances, consuming significantly more fossil-fuel energy for transportation and emitting much more carbon dioxide than a few decades ago. [20] Lean manufacturing value streams typically have lower emissions due to reduced inventory being held internally at each company, but the frequent replenishment generally tends to increase emissions. As distances increase, it is quite possible for lean and green to be in conflict. Lean may be green in some cases, but not in others. 
The reverse logistics focuses primarily on the return of recyclable or reusable products and materials into the forward supply chain.[21] To reintroduced recycled materials, components and products into the downstream production and distribution systems, it is necessary to integrate reverse material and information flows in the supply chain. Due to the reverse material flow, traditional production planning and inventory management methods have limited applicability in remanufacturing systems. Therefore, it is necessary to consider the existence of the returned items that are not yet remanufactured, remanufactured items and manufactured items.

\subsection{Lean for Better Environmental Management}

Some researchers have established links between the occurrence of practices that support manufacturing sustainability and firms adopting lean manufacturing strategies. This work attributes the mutual benefits between lean production and environmental management practice to the reduced waste and continuous improvement philosophies of lean.

The objective of lean is to generate a system that is efficient and well organised and devoted to continuous improvement and the elimination of all forms of waste. The potential for a benefit to manufacturing SMEs environmental management practice is high. The practices that support lean manufacturing are similar to the practices that support environmental performance. Lean production is broadly described as an integrated approach to the management of a manufacturing organisation, that encompasses a wide variety of practices, including JIT, quality systems, work teams, cellular manufacturing and supplier management. The lean production philosophy focuses on avoiding seven forms of waste and on respecting customers, employees and suppliers [7][8][32]. A sizeable body of empirical work supports the capacity of the lean system to remove continuously multiple forms of waste, smooth production flow, improve understanding of human resource management issues, maintain quality and increase customer service, while also yielding a significant competitive advantage.

\section{Industrial Use Case}

\subsection{DMAIC Methodology}

There are two major methodology approaches that have been reported in the literature for implementing lean, the DMAIC (Define-Measure-Analysis- ImproveControl) and the DMADV (Define- Measure-Analysis-Develop-Verify) [37][33]. The DMAIC approach is recommended for analyzing and improving the existing product or process, while the DMADV approach is appropriate for designing new product or process.

An exploratory six sigma case study conducted at the parent company based on the five phases of the methodology: Define, Measure, Analyze, Improve and Control (DMAIC) is described shortly. The DMAIC approach is described which was used to dig deeper into the non-conforming components received by the parent company from 
two tier-one suppliers. This exploratory case study were conducted within the energy industry in order to examine the nature of the complex interactions between the two major constructs lean and environmental sustainability at the parent company and its first tier vendor. Interviews were conducted with key purchasing, production and environment staff within the parent company and case study conducted with one firsttier parts vendor. Interviews with at parent company (government owned, around 15000 employees worldwide) were selected from a sample that represented major groups of responsibility and decision making.

At the first tier vendor (privately owned, around 220 employees, supplies foundry and special sub-assembly components, supplies about 80 per cent of their business to the parent company) two- to three-hour semi-structured interviews were conducted with the operations manager, production supervisor and quality/environment manager. A site tour was conducted to look specifically at shop floor layout, warehouse and receiving inspection areas. The relevant stakeholders completed a self-assessment questionnaire at the completion of the site visit.

\section{DMAIC Process}

\section{A. Problem Definition}

Defining the problem is the most important step in Six-Sigma project since better understanding of the problem at this stage will help at the later stages of the project. In order to define the objectives of the project, manufacturing company's claims were investigated. The management needed to resolve the problem of long process lead time. The relevant KPIs were be identified, linked and then measured.

The critical-to-quality (CTQ) indicator was defined as below:

$\mathrm{CTQ}=$ Identified Defects / Shipment Flex Hoses per year

The company claimed that reducing the hose non-conformance issues by $50 \%$ would help the company save USD17,629.

\section{B.Measuring the scope of problem}

During the measure phase, the various non-conformance issues with the incoming components from the vendor were identified and measured in scope using company proprietary software. The top root causes were identified against the parent company's requirements and standards. The detailed product hierarchy and its relation to the final product assembly is confidential.

The attribute agreement analysis was conducted using data from the company's SAP system which also had the appraisers within the company which were needed to make the assessment. The questionnaire was provided to the appraisers from the company in free-text format. 
The operational definitions of defect and opportunity defined by the company are shown in a flowchart in Figure 2. The measurement system for defect and opportunity was capable as the Kappa values in the test exceed the allowable value of 0.7 .

\section{DEFECTS}

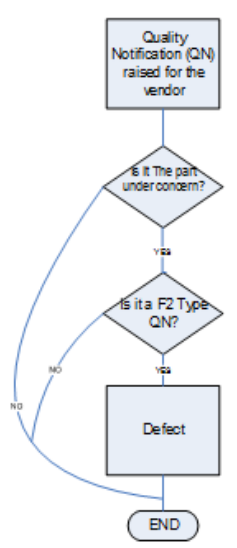

\section{OPPORTUNITY}

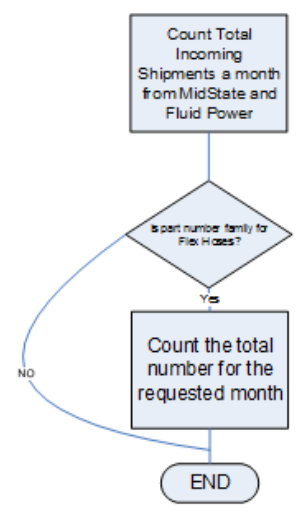

Fig. 2. Operational definitions

\section{Analyze the causes}

After the first two phases of DMAIC approach, it was decided to focus on the improvement plan to reduce the non-conformances. It was important to further study the potential causes/key input variables (KPIVs) of the non-conformances using 4M (man, machine, material, method) categorization method. Additional cause and effect matrix analysis was conducted in which key output variable (KPOVs), nonconforming product/incoming shipment was selected as the performance measure. A hypothesis test was conducted to compare the capability of the two vendors for the commodity resulted in a P-Value $=0.768$ which demonstrated no significant difference in the capability between vendors. One of the vendor related issues uncovered were, for example, missing incorporating the purchase order requirements from the parent as a part of the vendor's internal assembly .

\section{Improve the exiting processes}

The improve phase consisted of several activities organized to address the nonconformance causing factors. Onsite vendor meetings were organized to discuss engineering drawing requirements, company and industry-wide standards and the importance of compliance to the requested specifications. With the agreement of internal company stakeholders processes were updated to incorporate the suggested improvements.

\section{E.Control}


The control phase is the last stage for the DMAIC approach. A control plan was design and introduced to the production line. The plan provides a summary of the control application which aims to minimize the process variation and ensures producing top quality products. In addition, the control plans guarantees that the proposed solution is properly implemented and monitored. It was reported that as a result of the recommendations, the customer claim rate was reduced by $55 \%$.

\section{Results : Parent Company}

At the parent company the following early results were obtained:

- Greater than 80 per cent of respondents believed that the greatest influence of the parent company over the vendor's environmental management practices occurred during sourcing and to a lesser extent (but still possible) during production trials. Greater than 70 per cent of respondents did not believe that it was possible for the parent company to influence or develop a vendor's environmental management practices during ongoing production.

- The majority agreed that the following situations would encourage them to discuss with, monitor and assess a vendor's environmental performance: if it presented a risk to the parent company's production system; and if it was a well documented, resourced and standardized aspect of their purchasing.

\section{Tier-one Vendor Company}

The vendor had undergone a lean transformation with the direct assistance of the parent company. The vendor had not obtained ISO 14000 certification. The following early observations were gathered at the vendor:

- The commitment to ongoing process improvement an meeting the requirements of the customer at this plant was high. The customer's requirements for environmental performance were a more important driver for change than the regulatory environment.

- The culture for improvement at the vendor was strong, with worker involvement high and worker attitude towards change, highly positive. Resources committed to the environment were very low however, and the SME appeared to be just keeping up with its lean transformation and its significant growth during the year.

When developing the kaizen implementation plan associated with the future state value stream map, it was noticed that continuous improvement events on certain processes may require special attention to EHS issues.

\section{Summary}

The current literature is abundant with discussion on the individual strategies, but has thus far not addressed how firms can implement these strategies concurrently. A thorough examination of the individual bodies of literature was used as 
a means to guide future research at the intersection of green and lean strategies. The future research agenda addresses gaps in the current literature, and suggest relevant framework from which to explore this phenomenon. The agenda presented in this paper allows for future research that begins to meet the call for potential work.

In terms of limitations, this research paper makes use of only one case study. Though the case study demonstrate useful insight into working through quality processes and integrating environmental concerns into already in place quality management system; this is simply the start. Research investigating this integration with other manufacturing models outside of the energy business is planned in the near future.

\section{References}

[1] Bey N., Hauschild M.Z., McAloone T.C: Drivers and barriers for implementation of environmental strategies in manufacturing companies, Annals of the CIRP, Vol. 62, p.43-46 (2013)

[2] U.S. Department of Energy (USDOE): Energy and Environmental profile of the US metalcasting industry, Office of Industrial Technologies (1999)

[3] H. Flegel: MANUFUTURE Strategic Research Agenda. Report of the High-Level Group. Available: http://www.manufuture.org/manu facturing/wpcontent/uploads/ManufutureSRA-webversion. Pdf (2006)

[4] Hart, S.: A natural-resource based view of the firm, Academy of Management Review, Vol. 20 No. 4, pp. 986-1000 (1995)

[5] Florida, R.: Lean and green: the move to environmentally conscious manufacturing”, California Management Review, Vol. 39 No. 1, pp. 80-105 (1996)

[6] Toyota Motor Corporation, Department of innovation.

[9] P. Åhlström: Sequences in the Implementation of Lean Production, European Management Journal, vol. 16, pp. 327-334 (1998)

[11] J. K. Liker: The Toyota Way: 14 Management Principles From the World's Greatest Manufacturer. New York: McGraw- Hill (2004)

[12] R. Shah and P. T.: Ward Lean manufacturing: context, practice bundles, and performance, Journal of Operations Management, vol. 21, pp. 129-149, 2003 (2003)

[19] Srivastava, S. K.: Green supply-chain management: A state-of the- art literature review. International Journal of Management Reviews, Vol. 9, No. 1, pp. 53-80 (2007)

[20] Venkat, K. \& Wakeland, W. Is Lean Necessarily Green? Proceedings of the 50th Annual Meeting of the ISSS (International Society for the Systems Sciences) (2006)

[21] Shah, R. and Ward, P.: Lean manufacturing: context, practice bundles and performance, Journal of Operations Management, Vol. 21 No. 2, pp. 129-49 (2003)

[33] Wadhwa RS: Implementing Manufacturing Process Automation in Metalcasting Facilities, AFS, ISBN 978-0-87433-408-1 (2014) 